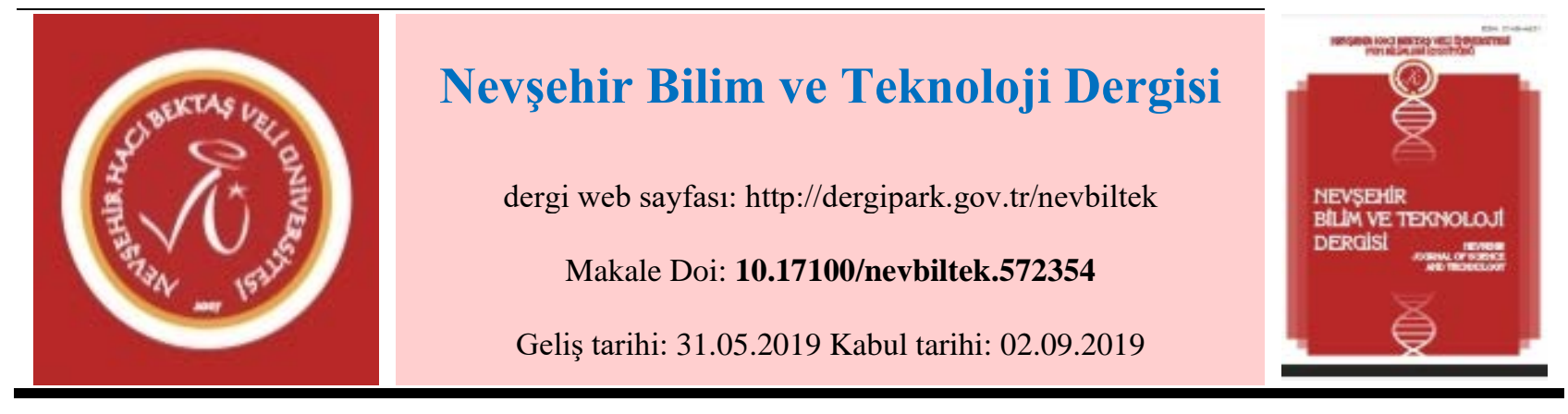

\title{
Otel Yapılarında Sürdürülebilir Yaklaşımlar ve Yeşil Bina Sertifikasyon Sistemleri 1
}

\author{
Serkan Sipahi ${ }^{1}$, Filiz Tavşan ${ }^{2}$ \\ ${ }^{1}$ Atatürk Üniversitesi, Mimarlık ve Tasarım Fakültesi, İç Mimarlık Bölümü, Erzurum, Türkiye \\ ORCID ID: 0000-0002-5684-8671 \\ ${ }^{2}$ Karadeniz Teknik Üniversitesi, Mimarlkk Fakültesi, İ̧̧ Mimarlık Bölümü, Trabzon, Türkiye \\ ORCID ID: 0000-0002-0674-2844
}

Öz

Bir yerin doğal, tarihi ve kültürel zenginlikleri, o yerin turizm açısından cazip hale gelmesini sağlamaktadır. Bu nedenle turizmin devamlılı̆̆ açısından turizmin yapıldığı yerdeki bu zenginliklerin korunması gerekmektedir. Doğal, tarihi ve kültürel zenginliklerin korunarak turizmin sürdürülebilirliğinin sağlanması konusunda ise turizm yapıları ve otellerin sürdürülebilir olması oldukça önemlidir. Binaların sürdürülebilirliklerini ölçen çeşitli sertifikasyon sistemleri mevcuttur. Bu sertfikasyon sistemleri içerisinde genel olarak LEED ve BREEAM sertifikasyon sistemleri yaygin olarak başvurulan yeşil bina sertifikasyon sistemleridir. Bu sertifikasyon sistemlerine otel yapıları için de başvurulmaktadır. LEED ve BREEAM sertifikasyon sistemleri, binaların çevresel etkilerini farklı alanlarda; bölümler halinde inceleyerek her yönden bina sürdürülebilirliğini ortaya koymaktadır. Binaların sahip oldukları puanlara göre ise derecelendirilerek sınıflandırma yapılmaktadır. Bu nedenle turizmin devamlılığı açısından otel tasarımlarında sürdürülebilirlik ve getirmiş olduğu yeniliklerin, sertifikasyon sistemleri aracılığı ile irdelenerek ortaya konulması gerekmektedir. Bu çalışmanın amacı LEED ve BREEAM sertifika almış otellerin yenilikçi yaklaşımlarının ortaya konulmasıdır. Araştırmada yöntem olarak mevcut durumun araştırılması ve tespit edilmesi amacıyla betimsel desen, literatür ve kaynak tarama kullanılmıştır. LEED ve BREEAM üst başlıklarına göre gruplandırılarak irdelenmiştir. Çalışmanın örneklem grubunu LEED ve BREEAM değerlendirme sistemlerinden seçimiş toplam 10 otel oluşturmaktadır. Sonuç olarak Otel tasarımlarında sürdürülebilirlik açısından nelere dikkat edilmesi gerektiği, örnekler üzerinden tartışılmış; yönetim, malzeme, kirlilik, su, enerji, sağlık ve konfor, iç mekan ortam kalitesi gibi konularda sürdürülebilir otel tasarımların nasıl olması gerektiği tartışılarak; otellerin sürdürülebilirlikleri konusunda LEED ve BREEAM kapsamında yapılan havalandırma, enerji kullanımı, suyun etkin kullanımı gibi konulardaki farklı ve yenilikçi yaklaşımlar ortaya konulmuştur.

Anahtar Kelimeler: Sürdürülebilirlik, Otel Mimarisi, LEED, BREEAM

\section{Sustainable Approaches in Hotel Buildings and Green Building Certification Systems}

\begin{abstract}
The natural, historical and cultural riches of a place make it attractive for tourism. Therefore, in terms of the continuity of tourism, these riches must be preserved where tourism is made. In order to ensure the sustainability of tourism by preserving the natural, historical and cultural richness, it is very important that tourism structures and hotels are sustainable. Several certification systems measure the sustainability of buildings. Among these certification systems, LEED and BREEAM certification systems are commonly used as green building certification systems. These certification systems are also applied for hotel structures. LEED and BREEAM certification systems, environmental impacts of buildings in different areas; examines the sustainability of the building from every direction by examining in sections. The aim of this study is to reveal the innovative approaches of the LEED and BREEAM certified hotels. In the research, descriptive design, literature and literature review were used as a method to investigate and determine the current situation. LEED and BREEAM are grouped according to their headings. As a result, what should be paid attention to in terms of sustainability in hotel designs is discussed with examples; discussing how sustainable hotel designs should be on issues such as management, material, pollution, water, energy, health and comfort, indoor environment quality; different and innovative approaches to the sustainability of hotels within the scope of LEED and BREEAM are discussed.
\end{abstract}

Keywords: Hotel, Sustainability, LEED, BREEAM, Hotel Venues

\footnotetext{
${ }^{1}$ Bildirimizin özeti "2nd International Congress on Engineering and Architecture " kongresinde özet olarak sunulmuştur. Sorumlu yazar e-mail: serkansipahi@hotmail.com
} 


\section{Giriş}

Turizm ve turist sayıları her geçen gün tüm dünyada artmaktadır. Ülkemiz turizm sektörünün büyüme hızı ise dünyadaki genel büyüme hızının üzerindedir [3]. Bu artışın ekonomik kalkınma açısından ülkemiz için olumlu etkileri vardır ancak bununla birlikte sürdürülebilir kalkınma sorumluluğunu da gelecek nesiller için beraberinde getirmektedir.

Turizm endüstrisinin çevresel etkileri incelendiği zaman tüm turizm sektörünün dünyadaki SEG ve CO2 emisyonlarının yaklaşık yüzde 5'ini ürettıği görülmektedir. Dünya geneline bakıldığında yapılar temiz su kaynaklarının yüzde 17'sinin, orman ürünlerinin yüzde 25'inin ve enerji kaynaklarının yüzde 40'1nın tüketiminden sorumludur. Yapılan araştırmalar göstermiştir ki, turizm yapıları da yüzde 20 gibi bir pay ile bu tüketime ortak olmaktadırlar. Turizm yatırımlarının çevreyi minimum tehdit eder düzeye gelebilmesi için $\mathrm{CO} 2$ ve SEG emisyonlarını bugünkü düzeyden yaklaşık yüzde 30-40 aşağı çekmeleri gerekmektedir [2]. Turizm sektörünün çevresel etkilerinin oldukça fazla olmasının yanında turizm sektörünün geliștiği alanların doğal çevre bakımından oldukça kırılgan bir yapıya sahip olması da önemli bir sorundur. Doğal çevre bağlamında turizm aktiviteleri çevreyi çekici kılan nedenlerden dolayı çoğunlukla daha kırılgan ve hassas olan bölgelere çekilmiștir

[4]. Dolayısıyla turizmin var olması için çevrenin yaşaması (sürekliliği) gerektiği ve doğanın (çevrenin) aleyhine gelişen bir turizmin kendi kaynağını tüketeceği sonucu kaçınılmazdır [1].

Turizm sektörü için sürdürülebilir turizm başlığı altında kalkınma planları hazırlanmaktadır. Bölge planlamaları yapılarak çevresel etkilerin en aza indirgenmesi hedeflenmektedir. Bu planlamaların yanında turizm yapılarının sürdürülebilirliklerinin sağlanması ve denetlenmesi turizm sektörü açısından önemli bir gerekliliktir.

Tarihi, kültürel ve sosyal yapıların ve alanların sürdürülebilir bir biçimde korunarak geliştirilmesi gerekmektedir. Bu alanlar turizm sektörünün ana temasını oluşturmaktadır. Bu yapı ve alanların bütünlüğünü bozacak yapım ve işletmelerden kaçınılmalıdır. Bu aşamada özellikle doğal alanlarda tasarımcılar tarafından bilinçsizce yapılan tasarımlardan kaçınılmalı tarihi yapı çevresindeki benzeşik yeni yapıların oluşturulmasına izin verilmemelidir.

Bunun yanında bu alanlardaki işletmelerin atık yönetimleri incelenmeli yapı ve alanlara verilecek her türlü zarar engellenmelidir.

Unutulmamalıdır ki turizm yapılarının ve turizm sektörünün sürdürülebilir şekilde yönetimi turizm sektörünün devamlılı̆̆ açısından bir gerekliliktir.

Turizm sektörü içerisinde çevresel etkiye en fazla sahip bina grubu ise otellerdir. Sürdürülebilir Otel kavramı daha az enerji ve su tüketen, $\mathrm{CO} 2$ emisyonları azaltılmış, küresel iklim değişikliğine pozitif etki sağlayan, çevre dostu yerel ve geri dönüştürülebilir malzemeler ile inşa edilmiş ve yatırımcısının sosyal ve çevresel sorumluluğunu belgeleyen bir kavram olarak ortaya çıkmaktadır' [5].

Turizm yapıları ve otellerde de sürdürülebilirlik; diğer yapı türlerinde olduğu gibi yeşil bina sertifikasyon sistemleri yardımı ile irdelenmektedir. Sürdürülebilir bir otel, tüm binaların çevresel performanslarını değerlendiren LEED, BREEAM, DGNB gibi sertifika programları ile değerlendirilebildiği gibi, Green Globe, Green Key, Eu Eco Label gibi sürdürülebilir otellere özel geliştirilmiş değerlendirme programları ile de değerlendirilebilir. Türkiye'de ise Turizm Bakanlığı tarafından geliştirilen "Yeşil Yıldız" ve TÜROFED tarafından geliştirilen "Beyaz Yıldız" sertifikaları çok kapsamlı çalışmalar olmamakla birlikte, yine de bir otel yapısının sürdürülebilirliğini değerlendirmek için yapılmış çalışmalardır [5]. Bu nedenle yeşil bina sertifikasyon sistemlerine sahip otel yapıları turizmin sürekliliğinin sağlanması nedeni ile mimari açıdan irdelenmeli ve bu yapılarda kullanılan sistemler yaygınlaştııılmalıdır.

$\mathrm{Bu}$ çalışma kapsamında yurt içi ve yurt dışı sürdürülebilir otel mekânlarına ilişkin çeşitli örnekler incelenmiştir. Otellerin sürdürülebilirlikleri konusunda nelere dikkat edilmesi gerektiği bu örneklerle daha iyi anlaşılmaktadır

- $\quad$ Yeşil Bina Sertifikasyon Sistemleri

Yeşil bina sertifikasyon sistemlerrinin ortaya çıkışı incelendiği zaman; sürdürülebilirliğin kavramsal boyutunun ortaya konulmasıyla bu kavramın uygulanması ve pratiğe dönüştürülmesi gerekliliği ile birlikte ortaya çıktığı görülmektedir. Mimarlık alanının oluşturduğu çok disiplinli ortamda bu disiplinleri, belirli konu başlıkları altında toplanarak bir ara yüz oluşturulmuş; bu ara yüzler sayesinde sürdürülebilirlik kavramının mimarlık alanına kullanıcıların daha bütünsel ve kolay bakabilmeleri sağlanmıştır.

$\mathrm{Bu}$ ara yüzler binaların belirlenen çevresel performans kriterlerine uygunluğu ve bu konudaki başarılarını ölçerek derecelendirmek üzerine kurulmuştur. Ara yüzlerde bu ölçüm ve derecelendirmeler için belirli metotlar benimsenmiştir. Bu metotlar yapı tiplerine göre farklılık göstermektedir ve mevcut ya da yeni yapılmakta olan yapılara uygulanabilmektedir.

Ara yüzlerle yapılan değerlendirmeler sonucu belirli sertifikalar alınmaktadır. Bu sertifikalar zorunlu olmamakla birlikte binaların prestij bakımından artmasına otomatik olarak reklamlarının yapılmasına sebep olarak yapı endüstrisini sürdürülebilirlik konusuna teşvik eden sistemleridir. 
Sertifikasyon sistemlerinin temelleri, ilk olarak 80 yı öncesinde İngiltere'de atılmıştır. Uluslararası geçerliliği olan ilk ara yüz ise 1990 yılında yapılan Bina Araştırma Çevresel Değerlendirme Metodu (BREEAM: Building Research Environmental Assesment Method)'dur. BREEAM'ın yapılmasından sonra çeşitli ülkeler tarafından çeşitli ara yüzler ve sertifika sistemleri geliştirilmiştir. Bu geliştirilen ara yüz ve sertifika sistemlerinden günümüzde BREEAM'la birlikte en yaygın kullanılanları ise; BREEAM sertifikasyon sistemi ile birlikte Amerikan Yeşil Bina Konseyi tarafından 1998'de oluşturulan Enerji ve Çevresel Tasarımda Liderlik (LEED: Leadership in Energy and Environmental Design)'dir [6].

$\mathrm{Bu}$ ara yüzlerin kullanımı geliştiricileri tarafından eğitilen değerlendiricilerle tüm dünyada giderek yaygınlaşmaktadır. Ülkemizde de bu ara yüzleri kullanarak sertifika modellerinden kazanmak için başvuran bina sayısı her gün artmaktadır.

\section{Materyal ve Metot}

Çalışmada dünya üzerinde en yaygın olarak kullanılmakta olan LEED ve BREEAM yeşil bina sertifikasyon sistemlerinde sertifika almış 10 otel yapısı irdelenemiştir. LEED sertifikasına sahip otellerin seçimlerinde LEED platinium sertifika derecesi almış otellerin yanı sıra ülkemizden bir örnek olması nedeni ile LEED gold sertifikasına sahip Hilton Garden Inn Golden Horn Sütlüce oteli örnek olarak irdelenmiştir. BREEAM sertifikasyon sistemine sahip oteller ise BREEAM tarafindan verilen mükemmel derecesine sahip otel yapıları ve fevkalade derecesine sahip tek otel olan Nh Ribera Del Manzanares Otel'den oluşturulmuştur. Seçilen oteller ve bulundukları şehirler ile almış oldukları sertifika tipleri tablo 1 . 'deki gibidir.

Tablo 1. Seçilen Otel Listesi, Bulundukları Şehirler ve Sahip Oldukları Sertifikalar

\begin{tabular}{|l|l|l|}
\hline \multicolumn{1}{|c|}{ Otel Adı } & \multicolumn{1}{c|}{ Bulunduğu Şehir } & \multicolumn{1}{c|}{ Sertifika Adı } \\
\hline Hotel Bardessono & San Francisco & LEED platin \\
\hline Hotel Skyler & New York & LEED platin \\
\hline Parkview Green & Hong Kong & LEED Platin \\
\hline Proximity Hotel & Kuzey Carolina & LEED Platin \\
\hline ITC Gardenia Hotel & Bangalore & LEED Platin \\
\hline Hilton Garden Inn & Sütlüce, İstanbul & LEED Gold \\
\hline Orchard Hotel Nottingham & Nottingham & BREEAM Mükemmel \\
\hline South Place Hotel & Londra & BREEAM Mükemmel \\
\hline Raddison Blu Hotel & East Midlands & BREEAM Mükemmel \\
\hline Nh Ribera Del Manzanares Otel & Madrid & BREEAM Fevkalade \\
\hline
\end{tabular}

\section{Bulgular}

Çalışma kapsamında seçilen oteller genel özellikleri ve sürdürülebilirlik açısından önemli özellikleri ile tanıtılmıştır.

\section{- Hotel Bardessono}

Leed platin sertifikasına sahip Hotel Bardessono Amerika'nın San Francisco eyaletinde bulunmaktadır.

Leed platin sertifikasını 2010 yılında almış olan bu ziyaretçilerine lüks bir ortam sağlarken bu lüksü çevreci seçimler yaparak sağlamıştır.
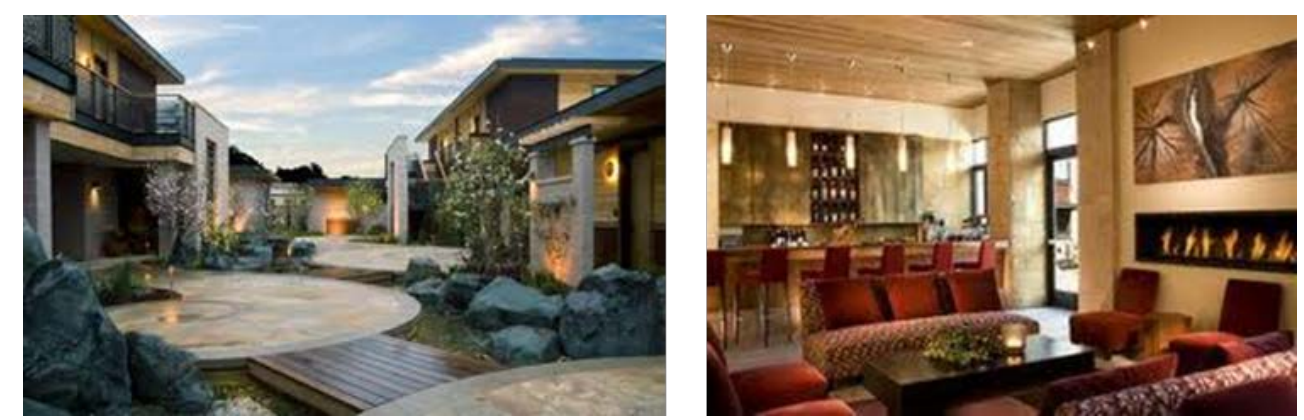

Şekil 1. Hotel Bardessono [7]. 
Otelde çiftçilerce telef edilmekten kurtarılan ağaçlar kullanılmıştır. Taşıyıcı sisteminde toksin ve alerjik olmayan malzemeler vardır. Organik kumaşlar ve temizleme malzemeleri, Geri dönüşüm ve gübreleme programları ise standart olarak mevcuttur.

Restoran ve spa bünyesindeki üretimin kaynak ihtiyacında öncelik yöresel, organik veya sürdürülebilir üreticilere verilmiştir [7].

$\mathrm{Bu}$ otelde dış enerji kaynakları olan elektrik, gaz ve yakıt benzer nitelikte bir otele göre \%50 daha az kullanılmaktadır. Otele gün ışığı maksimum düzeyde gelirken kapı ve pencereler doğal havalandırmayı en iyi şekilde sağlayarak doğal havalandırmanın ana havalandırma elemanı olmasını sağlamıştır.

Camlar 1Sı geçişini azaltmak amacıyla özel olarak seçilmiştir. Sensörler yardımıyla ziyaretçiler odada olmadığında termostatlar otomatik olarak kapalı konuma gelmektedir. Soğutma ihtiyacının karşılanması amacıyla, güneş kırıcı elemanların açısı otomatik olarak değişmektedir. İç mekânda yansıtıcı malzeme seçimi de 1sı enerjisinin azaltılmasında etkili olmuştur.

Tüm bu ısınma ile ilgili önlemlere ek olarak otel geneli ve kullanım suyunun isıtılmasında yeraltı sıcak suları kullanılmaktadır. Bu sular yer altında $70{ }^{\circ} \mathrm{C}$ 'de bulunmaktadır. Bu sular bütün otelin sıcak su ihtiyacı ve 1sıtmasını karşılarken enerji sadece devir daim ve su pompalanmasında kullanılmaktadır.

Işık geçirgenliği yüksek camlar sayesinde gündüz vakitleri ışık gereksinimleri en aza indirilmiştir. İç mekanda ise halojen veya floresan lambalar kullanılarak 1şıklandırmada harcanan enerji azaltılmıştır. Dış mekânda kullanılan lambalarda ise ışık kirliliğini en aza indiren lambalar tercih edilmiştir. Odalarda sensörler yardımıyla müşteriler odada olmadığında ışıklar otomatik olarak sönmektedir.

Güneş enerjisinden elektrik enerjisi üretme konusunda maksimum seviyede faydalanılmıştır. Güneş enerjisi yardımıyla elektrik tüketimi en aza indirilirken bu sistemin kendisini 6 ile 10 yıl arasında karşılaması hedeflenmiştir.

Geleneksel bir teknik olan "tufa" adı verilen doğal malzemeler olan taş ve kireç ile yapılan bir sistem kullanılarak otelin dış duvarları oluşturulmuştur. Zeminde kullanılan ahşaplar ise çiftçiler tarafından yakılan ağaçların toplanarak öğütülmesiyle yapılmıştır. Bunlar dışında malzemelerin büyük bir kısmı üretim yerleri 500 millik bir alan içinde olan üreticilerden alınmıştır. Bu malzemelerin taşınmasında harcanan enerjiyi en aza indirmiştir.

İç mekân hava kalitesinin daha iyi olması için bütün yapsştırıcı, kaplama malzemeleri, kumaşlar, boya malzemeleri düşük uçuculuğa sahip olmayan organik bileşenlerden yapılmıştır. Mobilyalar iç mekana alınmadan önce iç mekanda tozların temizlenmesi amacıyla iç mekan fanlarla saatlerce havalandırılmıştır. Bunun yanında mobilyada kullanılan bütün kumaşlar yeşil sertifikalı kumaşlardır. Plastik kullanımı en aza indirgenmiş olup kullanılan porselen ve seramikler dönüştürülebilir doğal malzemelerdir. Halı ve kilimlerde yeşil sertifikalı diğer ürünlerdir. İç mekânda kullanılan banyo aksesuarları düşük su akışlı, sifonlar ise çift kademelidir.

Dış mekânda ise su tüketimini azaltmak için peyzaj düzenlemesinde kurak iklim bitkileri kullanılmıştır. Sulama sistemleri maksimum verimlilik hedeflenerek tasarlanmıştır.

Yapının inşaat alanının çevresi 35 feet’ten itibaren aynen korunmuştur. İnşaat alanı mümkün olduğunca küçük tutulmuştur. Bunun dışında yapı sistemlerinde kullanılan inşaat malzemelerinin \%95'i geri dönüşümlü malzemelerdir [7].

\section{- Hotel Skyler}

New York'ta bulunan Hotel Skyler Leed platin sertifikasını Amerika'da alan 3. oteldir. 58 odası bulunan bu otelde jeotermal ısıtma sistemi kullanılarak zeminden alınan ısı kullanılmaktadır.

Led lambalar merkez alanlarda kullanılırken, odalarda floresan lambalar kullanılmıştır. Energy saver kart sistemi ile kullanıcılar odalarında olmadığı zaman ısıtma ve soğutma sistemleriyle birlikte oda elektriği tamamen kapalı hale gelmektedir. Çıkış ve koridor ışıkları ise kart kaldırıldığında otomatik olarak yanmaktadır [8].
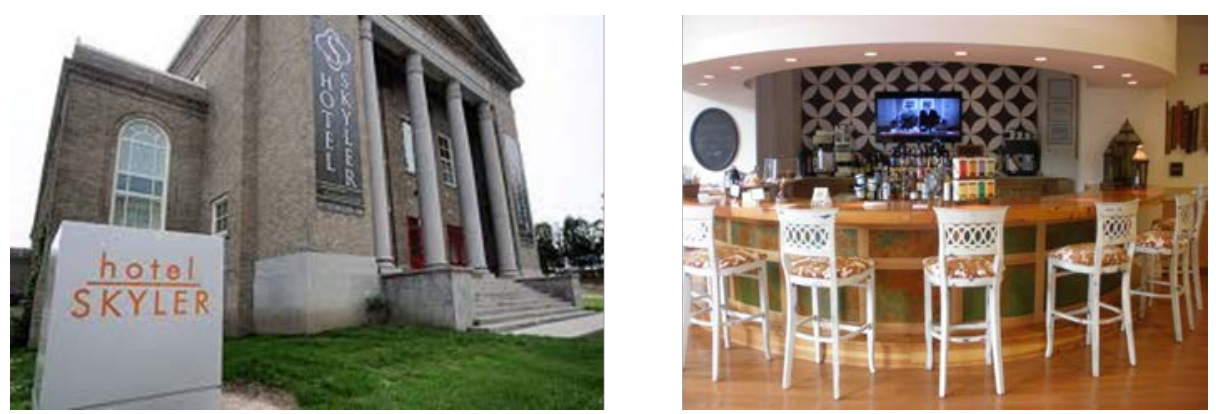

Şekil 2. Hotel Skyler [8]. 
Yağmur suyu toplama ve arıtma sistemleri otel binası ve otopark alanlarında bulunmakta ve bu sayede yılda 500,000 'den fazla galon su depolanmaktadır.

Otelde bölgesel malzemeler kullanılmıştır. Bunun yanında inşaat alanından çıkartılan malzemelerin \%75 i geri dönüştürülmüştür. Yapıda kullanılan malzemelerin tamamı çevreye dost malzemelerden seçilmiştir.

\section{- $\quad$ Parkview Green}

Parkview Green, LEED Platinum sertifikalı, A sınıfı ofis alanına ve alt yıldızlı bir otele ev sahibi yapan karma bir binadır. Parkview Green Cam ve ETFE (etilen tetrafloroetilen) içindeki 4 binadan oluşmaktadır. ETFE, mikro iklim yaratıp yaşam döngüsünü korumaya, enerji tasarrufu yaptırmaya ve elektrik faturalarını minimum seviyede tutmaya yaramaktadır.

Parkview Green, LEED Platinum sertifikalı, A sınıfı ofis alanına ve alt yıldızlı bir otele ev sahibi yapan karma bir binadır. Parkview Green Cam ve ETFE (etilen tetrafloroetilen) içindeki 4 binadan oluşmaktadır. ETFE, mikro iklim yaratıp yaşam döngüsünü korumaya, enerji tasarrufu yaptırmaya ve elektrik faturalarını minimum seviyede tutmaya yaramaktadır.

Proje, Hong Kong merkezli mimarlar grubu Integrated Design Associates tarafindan tasarlanmış olup, Arup firması da cephe, yangın, fizik yapı, geoteknik ve trafik münendisliği dahil olmak üzere tam bir destek paketi sunmuş durumdadir [9].

Pasif ve aktif çevreci özellikleriyle bu binada, iç mekana girmeden önce yer altından hava veren ön soğutma sistemi, soğutulmuş tavan radyant soğutma sistemi ve yerden klima, benimsenen çevreci özellikler arasındadır. Bu iyi yönetilen aktif ve pasif sistemler, önemli derecede soğutma ve ısıtma için harcanan enerjiyi azaltmaktadır.
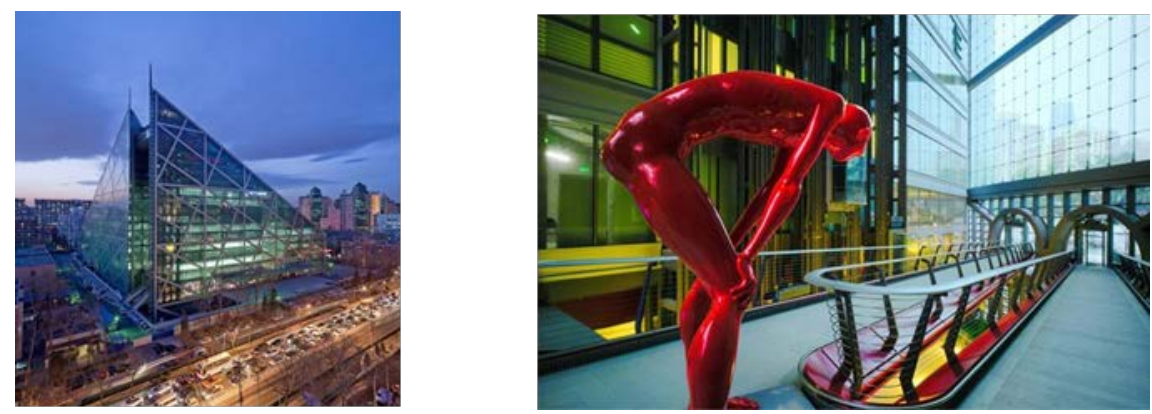

Şekil 3. Parkview Green [9].

Diş mekân 1Sısı uygun olduğu zamanlar, hibrid havalandırma sistemi, doğal havalandırma ve ücretsiz havalandırmaya izin verir. Bu hibrid sistem, geleneksel ofis havalandırma sistemi ile karşılaştırıldı̆̆ında \%60'a kadar enerji tasarrufu yapmaya olanak sağlar [9].

$\mathrm{Su}$ tasarrufu amacıyla, pis ve yağmur suyu geri dönüşüm sistemi kullanılmaktadır. Çatıda ve kaplamalı yerlerden toplanan yağmur suyu peyzaj alanında sulama için kullanmadan önce ön filtrasyondan geçer. Lavabo, duş ve musluklardan atılan sular da sifon ve peyzaj sulama işlemleri için kullanılmak üzere işlenir.

Malzeme seçimi, tamamen sürdürülebilirlik dikkate alınarak yapılmıştır. Bu yüzden, yapı malzemelerinin seçiminde, geri dönüşebilir malzemeler tercih edilmiştir. Yapı malzemelerinde kullanılan geri dönüşebilir maddelerin içerisinde dönüştürülmüş çelik ve ETFE de vardır. Ayrıca inşa için yumuşak ağaç türleri kullanılmıştır. Sulama ve peyzaj yönetimi azaltmak için yerel bitkiler tercih edilmiştir.

\section{- Proximity Hotel}

Proximity Hotel, Greensboro, Kuzey Carolina'da bulunan, Amerika Birleşik Devletlerinin ilk Platinum LEED sertifikasına sahip otelidir. Bu 147 odalı lüks butik otel $460 \mathrm{~m}^{2}$ 'den oluşmuş bir alanı kaplar. Otelin inşa kısmında 70ten fazla geri dönüşebilir madde kullanılmıştır ve doğa dostu otel inşaatının örneklerindendir.

$\mathrm{Bu}$ otel, son derece verimli malzeme ve en son inşaat teknolojisi kullanarak, geleneksel bir otel-restorana göre \%41 daha az enerji kullanmaktadır. Mutfağın ihtiyacına göre gücünü kendi ayarlayan yeni tasarlanmış değişken-hızlı davlumbazlar çok daha düşük seviyede elektrik harcamaktadır. Bu davlumbazlar tam kapasite ile çalıştıklarında \%25'e kadar tasarruf sağlayabilmektedirler. Otis asansör firmasının Kuzey Amerika'nın ilk Re-jeneratif Disk modeli olan Gen2, sistem tarafından kullanılan enerjiyi düşürüp binanın iç elektrik şebekesini beslemektedir. "Enerji geri kazanımı” teknolojisi kullanılarak odaların içerisine büyük miktarda dış ortam havası pompalanmaktadır ve havanın kalitesi iyileştirilmektedir. Otelin inşaatında nakliyat ve malzemenin hava kirliliğine neden olmaması için, yerel satıcılar ve sanatçılar kullanılmıştır [10]. 

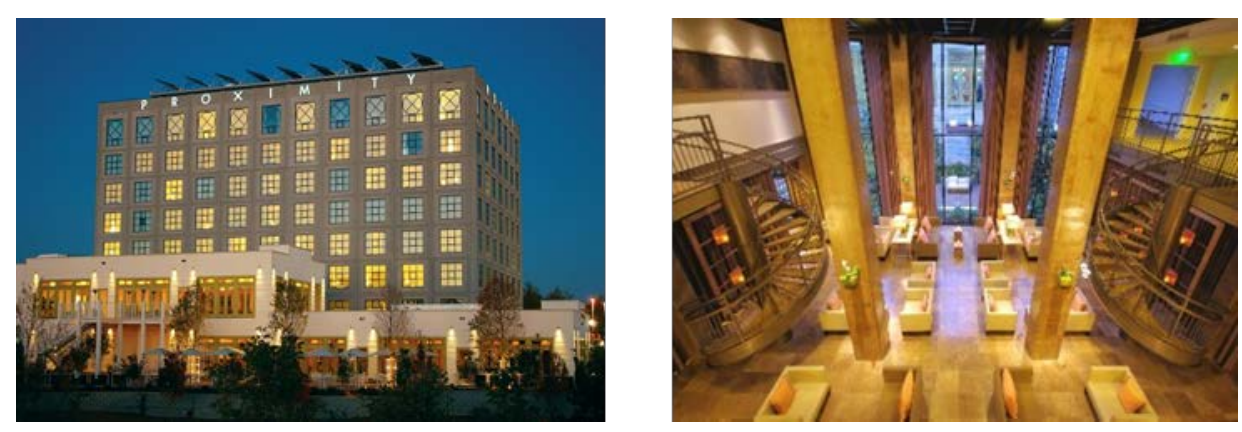

Şekil 4. Proximity Otel [10].

Çatının üst tarafında bulunan ve 370 metrekarelik bir alana sahip 100 güneş paneli, otel ve restoranda kullanılan suyun $\% 60$ 'ını 1sıtmaktadır. Restoranın soğutma ekipmanları için standart su soğutmalı sistem yerine jeotermal enerji kullanılmaktadır. "Kentsel ısı adası etkisi” yaratmak amacıyla çatının üst tarafına doğa dostu yeşil bir bitki örtüsü yaptırılmıştır.

Su kullanımı yüksek verimli sıhhi tesisat armatürleri sayesinde $\% 33$ oranında azaltılmıştır.

Bistro barı, firtına ya da hastalıktan yıkılmış, geri dönüşebilir katı ceviz ağacından ve oda servisi tepsileri ise Plyboo (bambu kontrplak)'dan yapılmıştır. Kullanılan uçucu organik bileşik (VOC) boyalar, yapıştıııcılar, halı, vb. iç mekân hava kirliliği azaltmak için kullanılmıştır. Odalardaki raflar ve restoranda kullanılan masaların kaplamaları \%100 sanayi sonrası dönüştürülmüş formaldehit eklenmemiş kağıt hamurunun üzerine ceviz kaplamadır.

Binanın inşaatında geri dönüştürülmüş madde kullanımı olarak \%90 geri dönüştürülmüş ve güçlendirilmiş çelik, $\% 100$ alçıpan, $\% 25$ asfalt ve $\% 50$ merdiven çeliği kullanılmıştır. 1535 ton ağırlığındaki inşaat atığının \%87 si geri dönüştürülmüştür [10].

\section{- $\quad$ ITC Hotels Gardenia}

Doğanın ihtişamını temsil eden ITC Gardenia Hotel Hindistan'ın Bangalore şehrinde bulunmaktadır. Bangalore şehrinin ticari kalbi olan yerde konumlanmış olan bu otel şehrin muhteşem bahçeleriyle özdeşleşerek 292 odayı bünyesinde barındırmaktadır.

Asya'nın ilk LEED sertifikalı oteli olma özelliğine sahip olan bu otel 5 yıldızlı bir otel olma özelliğine sahip lüks bir otel ve aynı zamanda su geri dönüşümü, enerji ve atık yönetimi, doğa dostu malzeme kullanımı gibi çevresel anlamda da iyi özelliklere sahiptir. Otelde aynı tip bir otele göre $\mathrm{CO}_{2}$ emisyonu \%60 daha azdır. Ayrıca içinde barındırdığı hastane ile de dikkatleri üzerine çekmektedir [11].
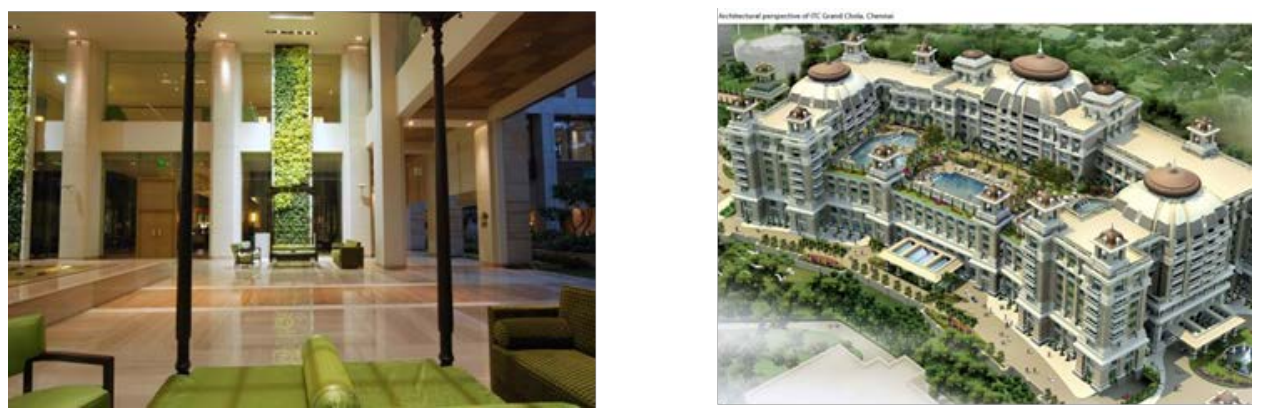

Şekil 5. ITC Hotels Gardenia [11].

Otelde iklimlendirme konusunda enerji kullanımına yönelik önlemler alınırken rüzgâr enerji tribünleri de doğa dostu enerji üretmektedir. Yemek pişirme eylemi konusunda tamamen güneş enerjisinden faydalanılmaktadır. Güneş enerjisi aynı zamanda rüzgar enerjisi ile birlikte tüketilen elektriğin tamamının üretilmesinde rol oynamaktadır. Ayrıca \%30 oranında iç mekânda doğal havalandırma vardır.

Otelde \%100 atık su dönüşümü yapılmakta ve bu sular temizlik, bahçe sulaması gibi alanlarda kullanılmaktadır [11]. $\% 50$ oranında orman ürünleri, $\% 10$ oranında geri dönüştürülmüş malzeme, $\% 5$ oranında hızlı yenilenen ahşap yapıda kullanılmıştır.

\section{- $\quad$ Hilton Garden Inn Golden Horn Sütlüce}

Hilton Garden Inn İstanbul Golden Horn Hotel'i, binanın yerleşimi ve mimari süreçten başlayarak çevresindeki doğa ve dokuya uygunluğu ile LEED kriterlerine göre projelendirilmiştir. Amerika dışında Gold sertifika düzeyinde bu 
sertifikayı alan ilk otel olan Hilton Garden Inn İstanbul Golden Horn Hotel, 2011 yılında açılmış Haliç’in ilk markalı otelidir.

Yerel ekonomiyi desteklemek ve yakıt tüketimi kaynaklı çevre kirliliğini önlemek için proje maliyetinin \%30’u yerel malzemelerden tercih edilmiş ve inşaat maliyetinin \%30’u geri dönüştürülmüş malzemelerden oluşturulmuştur. Binanın arsa şekline göre oturumu ve güneşı ışıllarını alma açısı değerlendirilerek, çatı alanlarında konumlanan solar paneller sayesinde 6 ay boyunca sıcak su güneş enerjisi ile temin edilmekte, güneşten maksimum fayda sağlanmaktadır [12].

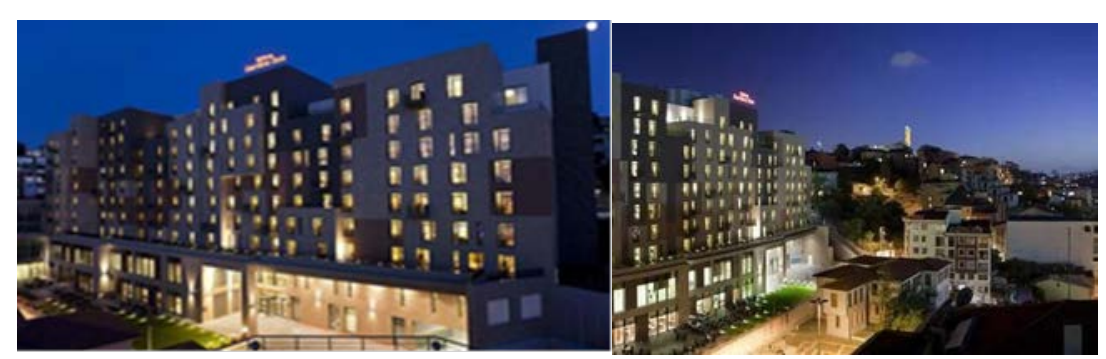

Şekil 6. Hilton Garden Inn Golden Horn Sütlüce [12].

Su tüketimini azaltmak için, peyzaj alanlarında az su tüketen yerel ve ortam koşullarına göre adaptasyon özelliği olan bitkiler tercih edilmiş, verimli bir sulama sistemi kullanılarak sulamada \%70 oranında su tasarrufu sağlanmıştır.

Dünyada ilk defa Hilton markasının uyguladığı “\%100 non smoking” yaklaşımı, LEED spesifikasyonları ile aynı kriteri benimsemekte, “\%100 non smoking uygulaması" Hilton Garden Inn İstanbul Golden Horn Hotel’inde de uygulanmaktır [12].

\section{- Orchard Hotel Nottingham}

Nottingham üniversitesinde 20 milyon Euro'luk bir bütçe ile 2012 y1lında hizmete giren Orchard Hotel'in yapımı esnasında otel çevresindeki elma ağaçlarına zarar gelmemesi için büyük çaba sarf edilmiştir. BREEAM sertifikalı bu otel çevresel anlamda son derece duyarlı bir yapıdır [13].

Otel tasarımında üniversite kampüsünden ilham alınmıştır. Bu özellikler bol miktarda ahşap, yöresel taşlar, çevredeki doğa ve ağaçların iç mekâna taşınmasında rol oynamıştır.
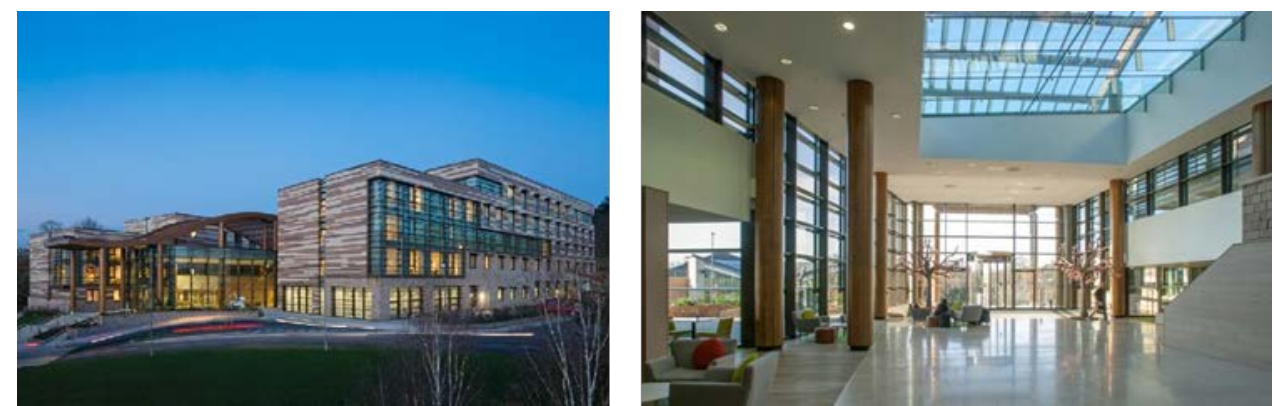

Şekil 7. Orchard Hotel Nottingham [13].

220 yataklı bu otelde $\mathrm{CO}_{2}$ emisyonları minimize edilmiştir. Güneş pillerinden Bina kütlesinde maksimum yararlanılmıştır. Çatıda çatı bahçesi oluşturulmuştur. Sensörler yardımıyla akıllı bina uygulamaları bu otelde mevcuttur [13].

Resepsiyon ve lobi alanlarının bulunduğu alanda cam çatı uygulaması mevcut olup bu alanda ahşap gölgelikler vardır. Mekânın komple cam olması gündüz vakitleri için mekanın hiçbir aydınlatma elemanına ihtiyaç duymamasını sağlamaktadır.

Zemindeki 1sı ve soğukluğu alarak ortak alanlarda kullanılmak üzere yükselterek yapı iklimlendirmesine katkısı olan bir sistem bu otelde mevcuttur. Bu sistem termal yalıtım açısından mükemmel bir uygulamadır. Bu sistemin kullanımı çevresel etkiler ve enerji kullanımı açısından son derece önemlidir [13].

\section{- $\quad$ South Place Hotel}

İngiltere'nin Londra şehrinde bulunan BREEAM sertifikalı bu otel 80 yatak kapasitelidir. Otelde sürdürülebilir yapım teknikleri kullanılmıştır. $\mathrm{CO}_{2}$ emisyonları yapıda eşdeğer bir yapıya göre \%40 daha azdır [14]. 


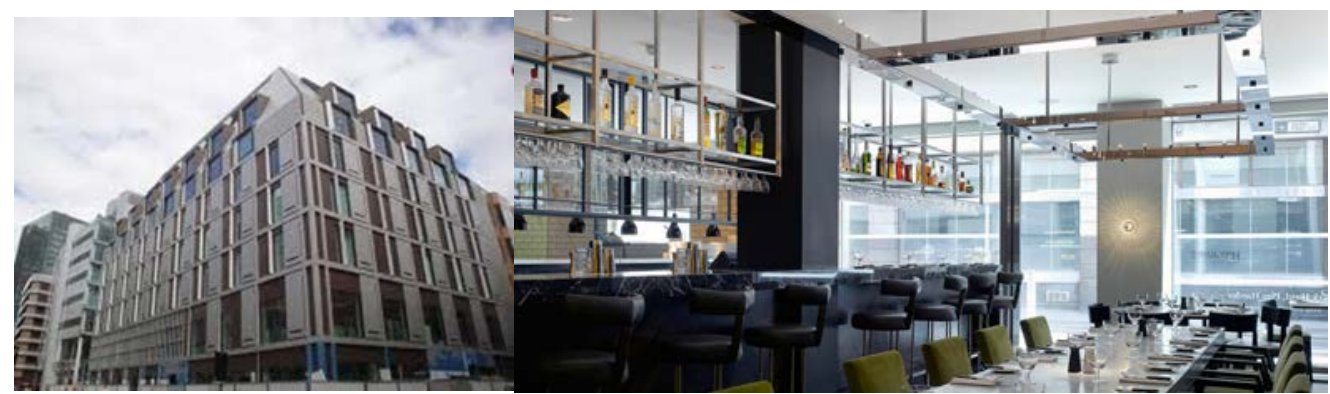

Şekil 8. South Place Hotel [14].

Otelde CHP(Combined Heating Power) adı verilen bir sistemle elektrik üretilebilmektedir. Bu sistem doğal yakıtların yakılması sonucu oluşan gazın tribünler yardımıyla elektrik üretmesi ve tribünlerden geçen gazın ikincil olarak yakalanmasıyla ikinci bir kazanı ısıtması ve son olarak soğuyan gazın iç mekân soğutmasında kullanılmak üzere saklanması şeklindedir [14].

Bunun dışında sensörler yardımıyla odaların hava durumu belirlenmekte ve odaların doluluk boşluklarına göre havalandırma ayarları yapılmaktadır. Otel restoran ve barları sürdürülebilir restoranlar birliğine üye olup bütün otel çalışanları geri dönüşüm ve atık yönetimi konusunda eğitim almışlardır.

\section{- $\quad$ Radisson Blu Hotel}

BREEAM sertifikasındaki almış olduğu \%76'lık puanla bu sertifikaya sahip oteller içerisinde en yüksek 2. puan almış olma başarısına sahiptir.

$\mathrm{Bu}$ otelde yaşam duvarı adı verilen sistemle iç mekân ve doğa bütünleştirilmiştir. Yaşam duvarı denilen sistem iç mekânda duvarların bitkilendirme yapıldığı bir sistemdir [15].

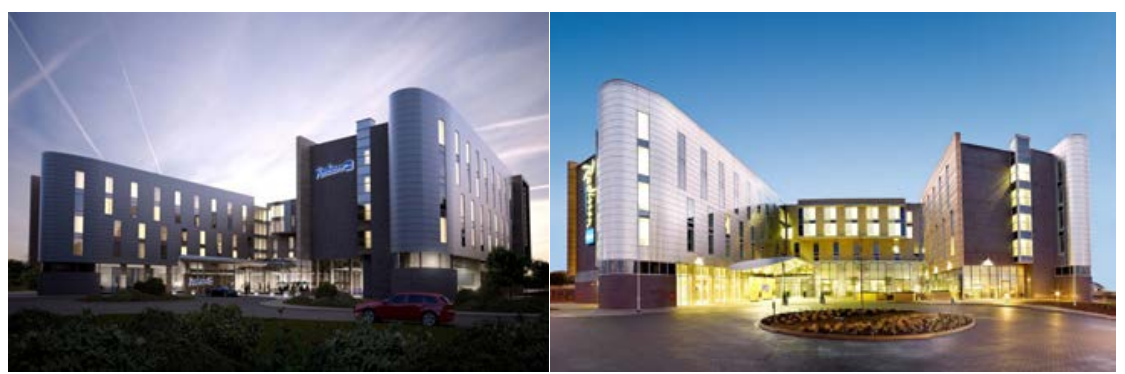

Şekil 9. Radisson Blu Hotel [15].

$\mathrm{CO}_{2}$ salınımı bu otelde eş değer otellere göre \%80 daha azdır. Bu durum LEED platin sertifikalı kimi otellerde bile \%50 civarlarında olduğu düşünülürse çevresel açıdan oldukça önem arz etmektedir.

Banyo ve tuvaletlerde tefrişatlar su kullanımını azaltmaya yönelik sistemlerden oluşturulmuştur. Bunun dışında yağmur suyu kullanımı da bu otelde son derece aktif olarak kullanılmaktadır. Sürdürülebilir cephe sistemiyle ve araba park yerlerindeki kaldırımların gözenekli oluşuyla yağmur suları toplanarak arıtılıp kullanılmaktadır.

Havalandırma ve elektrik sistemleri açısından CHP teknolojisi bu otelde de kullanılmaktadır. Bu sayede yapıda oldukça fazla enerji tasarrufu yapılmaktadır [15].

\section{- $\quad$ Nh Ribera Del Manzanares Otel}

2015 yılında yapılan Nh Ribera Del Manzanares Otel İspanya'nın Madrid kentinte bulunmaktadır. Yapı, BREEAM sertifikasyon sistemi kapsamında \%85'lik derece ile ilk “outstanding” fevkalade sertifika derecesi alan otel olmuştur [16].

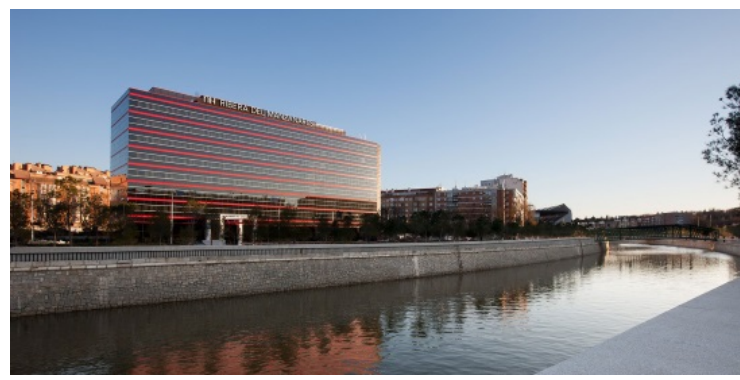




\section{Şekil 10. Nh Ribera Del Manzanares Otel [16].}

Yönetim, sağlık, enerji, ulaşım, suyun kullanımı, malzeme, kirlilik, yenilikler gibi BREEAM sertifikasyon sistemi kapsamında 10 kategoride değerlendirilen otel, Madrid şehrinde oluşturulmuş yeşil koridor alanında yer almaktadır [16].

Ziyaretçilerine yürüyüş ve bisiklet yolları, yeşil alanlar gibi imkanlar sunan otel aynı zamanda şehrin merkezinde yer alması ile bu imkanların şehirden uzaklaşmadan gerçekleştirilmesi ile ulaşım için harcanan enerjinin azaltılması ile çevreye katkıda bulunmaktadır [16].

Enerji ve suyun kullanımı konusunda çevresel etkileri oldukça düşük olan otelde karbon ayak izi konusu da oldukça detaylı irdelenmiş ve aydınlatma teknolojisi olarak LED teknolojisi kullanılmıştır [16].

\section{Tartışma ve Sonuç}

Turizm yapılarından turistlerin en fazla zaman geçirdikleri yerler olan otel yapılarında turizm sektörünün devamlılığı açısından enerji kullanımları mümkün olduğunca az ve çevreye duyarlı olmalıdır.

Dünya genelinde incelenen örnekler üzerinden otel yapılarında sürdürülebilirliğin saptanması amacıyla yapılmış olan bu çalışma kapsamında aşağıdaki sonuç ve önerilere varılmıştır.

- Otel yapılarında da diğer yapı türlerinde olduğu gibi enerji kullanımı çevreyi etkileyen önemli etmenlerden bir tanesidir. Enerji kullanımına yönelik olarak incelenen otellerde alternatif enerji kaynaklarına yönelim olduğu; bunun yanı sıra enerji tasarrufu sağlayan sistemlerin geliştirilmesine yönelik çalışmaların yapıldığı görülmüştür. Otel yapılarında enerji kullanımı için alternatif enerji kaynaklarına yönlenilmeli ve enerji tasarrufu için önlemler alınmalıdır. - Suyun tasarrufuna yönelik olarak otellerde birç̧ok çalışmanın yapıldığı görülmüştür. Yapılan çalışmalar gri su kullanımının arttırılarak suyun atık su ve yağmur sularının kullanılmasına yöneliktir. Gri su kullanımı ile birlikte yapılarda \%50'ye varan su tasarrufu yapılabildiği bilinmektedir.

- Doğal çevrenin korunarak doğal çevre ile turizmin birleştirilmesi gerekmektedir. Bu konu, sertifika almış birçok otel tarafından çalışmalar yapılarak bölge turizminin doğal çevre etkilenmeden gelişmesi sağlanmıştır.

- Malzeme hususunda yapılan araştırmalar sonucu yapıda kullanılan malzeme içeriklerinde VOC ve fenol formaldehit gibi bileşikler bulunmaması gerektiği görülmektedir. Bu bileşenler dışında kullanılan malzemelerin doğal ve yakın çevrede üretilen malzemeler olması gerektiği de görülmüştür.

- Gün ışığının etkin olarak kullanılması, yapay aydınlatmada az enerji kullanımı ve ışık kirliliğinin önlenmesi, havalandırma sistemlerinde doğal havalandırmanın etkin kullanılarak yapay havalandırmanın belirli bir program dahilinde en az enerji harcanarak sağlanması gibi konular da seçilen otellerde görülen diğer uygulamalardır.

- Ulaşım konularında otellerde yapılan incelemede bisiklet ve yaya yolları ile motorsuz ulaşımın desteklendiği ve toplu taşıma ulaşımının da düşünülerek ulaşım nedeni ile karbon salınımlarının en aza düşürülmeye çalışıldığı görülmüştür.

- Yapı ve çevresine yönelik çevresel etkilerin azaltılması amacı ile yapılan müdahaleler dışında yönetimsel anlamda da müdahaleler söz konusudur. Bu tip müdahaleler otellerin yaşam döngüsü içerisinde sürdürülebilirliğini, alınan ve alınacak kararlar bakımından etkilemektedir.

Sonuç olarak otel tasarımlarında bulunduğu yer farketmeksizin otellerin sürdürülebilirliğine önem verilmesi o yerin doğal çevresine katkıda bulunarak turizmin devamlılığını sağlayacaktır. Bu nedenle otellerin tasarım aşamasından itibaren sürdürülebilirliklerine önem verilmeli; sürdürülebilir yapım kapsamında oteller tasarlanmalı ve yapılmalıdır.

\section{Kaynaklar}

[1] ATAY, Lütfi ve DİLEK, S. Emre (2013), "Konaklama İşletmelerinde Yeşil Pazarlama Uygulamaları: İbiş Otel Örneği”, Süleyman Demirel Üniversitesi İktisadi ve İdari Bilimler Fakültesi Dergisi, S.1, C.18, s.203-219.

[2] MCKIBBEN, B., (2011), Dünya. E., Anıl, Çev.. İstanbul, Türkiye: İş Bankası Kültür Yayınları.

[3] KUNTAY, O., (2004), Sürdürülebilir Turizm Planlaması, Alp Yayınevi, 
[4] KURT, Suzan (2009), Çalışma Raporu (Turizm Yönetimi Ve Pazarlama Stratejileri), Kültür ve Turizm Bakanlığı, Aralık, 2009.

[5] CANBAY, N., (2012), Turizm Sektöründe Yükselen Trend Yeşil Oteller. Yeşil Bina Sürdürülebilir Yap1 Teknolojileri, Sept.-Oct. 9.

[6] http://www.usgbc.org/Docs/Resources/BDCWhitePaperR2.pdf 14 Kasım 2018.

[7] http://www.designcurial.com/news/watg-designed-bardessono-hotel-achieves-leed-platinum, 16 Mart 2019.

[8] http://dailyorange.com/2011/12/hotel-skyler-achieves-leed-certification/, 18 Mart 2019.

[9] http://chinaplus.cri.cn/news/business/12/20170428/3787.html, 20 Mart 2019.

[10] https://www.energydigital.com/sustainability/proximity-hotel-greenest-hotel-america, 22 Mart 2019.

[11] https://inhabitat.com/itc-royal-gardenia-the-world\%E2\%80\%99s-largest-leed-platinum-hotel/, 24 Mart 2019.

[12] https://www.voltimum.com.tr/haberler/leed-sertifikali-hilton-garden-innin, 25 Mart 2019.

[13] http://www.greenhotelier.org/our-news/industry-news/20-million-eco-hotel-opens-at-the-university-ofnottingham/, 26 Mart 2019.

[14] https://www.archdaily.com/282018/south-place-hotel-allies-and-morrison, 28 Mart 2019.

[15] https://www.emexlondon.com/30-overall-kwh-reduction-radisson-hotel-east-midlands-airport/, 28 Mart 2019.

[16] https:/www.nh-hotels.com/corporate/press-room/news/breeam-certifies-nh-ribera-del-manzanaresenvironmental-management-outstanding, 30 Mart 2019.

\section{Extended Abstract}

\section{Introduction}

The environmentalist views that started to be put forward since the beginning of the twentieth century increased with the second world war and at the beginning of the 1970s, it has found its place in national and international platforms all over the world. As a result of the researches carried out in this field, the concept of sustainability has been put forward. Sustainability studies are still in progress today.

There are studies in different areas related to sustainability. These studies range from education to industrial products and even to country policies. One of the areas where sustainability is addressed is the construction sector. The concept of sustainability in the construction sector targets resource use, environment and ecosystem conservation and energy management.

The concept of sustainability, which takes place in almost every field, is encountered with the requirements of water efficiency, energy conservation, material use and indoor air quality requirements in architecture and interior architecture. While the assessment of the solutions to these requirements is measured by many green building impact assessment tools, the focus is on sustainability in large buildings such as education, hospitals, terminals, shopping centers, where people function collectively. 
The natural, historical and cultural riches of a place make it attractive for tourism. Therefore, in terms of the continuity of tourism, these riches must be preserved where tourism is made. In order to ensure the sustainability of tourism by preserving the natural, historical and cultural richness, it is very important that tourism structures and hotels are sustainable.

Reducing the water consumed in hotels, ensuring the energy used from sustainable sources and consumption should be more careful. Waste should be recycled and the sustainability of the materials used inside and outside the building should be taken into account. The sustainability of these structures, which are mostly used by people for entertainment purposes, is important for the continuity of tourism and for leaving a green environment for future generations. For this reason, studies are underway to improve the architectural and interior architectural sustainability of hotel buildings all over the world; regulations are made in related regulations.

There are several certification systems that measure the sustainability of buildings. Among these certification systems, LEED and BREEAM certification systems are commonly used as green building certification systems. These certification systems are also applied for hotel structures. LEED and BREEAM certification systems, environmental impacts of buildings in different areas; examines the sustainability of the building from every direction by examining in sections. The classification is made according to the points they have. For this reason, the sustainability of tourism and the innovations it brings in the hotel designs in terms of the continuity of tourism should be examined through these two certification systems.

\section{Method}

The aim of this study is to reveal the innovative approaches of the LEED and BREEAM certified hotels. In the research, descriptive design, literature and literature review were used as a method to investigate and determine the current situation. LEED and BREEAM are grouped according to their headings. The sample of the study consisted of 10 hotels with the highest score from LEED and BREEAM evaluation systems.

As an example of the hotels with LEED certification, the hotel is also an example of a LEED gold medal. The hotels with BREEAM certification system have been created by BREEAM and the hotel is the perfect hotel, and is the only hotel in Nh Ribera Del Manzanares Hotel.

\section{Results and Discussion}

As a result, what should be paid attention to in terms of sustainability in hotel designs is discussed with examples; discussing how sustainable hotel designs should be on issues such as management, material, pollution, water, energy, health and comfort, indoor environment quality; different and innovative approaches to the sustainability of hotels within the scope of LEED and BREEAM, such as ventilation, energy use and effective use of water have been put forward.

Regardless of the hotel design, the importance of the sustainability of the hotels will contribute to the natural environment of the place and ensure the continuity of the tourism. Therefore, the importance of sustainability of hotels should be given from the design stage; hotels should be designed and built under sustainable construction. 